\title{
Femininities In The Discourse Of Khawateen Digest Of Pakistan
}

\author{
Asmat A. Sheikh \\ The Woman University, Multan \\ Naveed Ahmad \\ Bahauddin Zakariya University, Multan
}

\begin{abstract}
Khawateen Digest, an Urdu magazine, is one of the important repositories of feminine culture in Pakistan from many decades. This work attempts to explore Khawateen Digest for representation of women and provides a focus on the traditional and patriarchal female images. It endeavours to analyse issues of women as discussed in Khawateen Digest from the feminist perspective of Millet (1970) and Weedon (1987) who opine that women's social roles in patriarchal societies are defined by men. Moreover, at times, the use of language for secondary sex is not only exploitative but also sexually abusive in the respective magazine. The analysis centers on magazines as linguistic and semiotic constructs. The linguistic and semiotic content of the magazine has been encoded from a masculine and patriarchal perspective and the researcher has tried to decode it from feminist linguistic (Cameron 1998) perspective. Hence, this article is an effort to highlight the exploitative, demeaning, belittling, subjugating, subordinating, controlling and marginalizing representations of women through the analysis of linguistic and semiotic content of KHAWATEEN DIGEST.
\end{abstract}

Key Words: Khawateen Digest, Discourse, Patriarchy, Subjugation, Feminism.

$$
\begin{aligned}
& \text { تثخصن }
\end{aligned}
$$

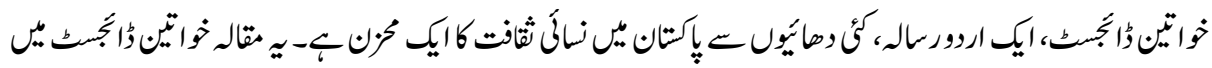

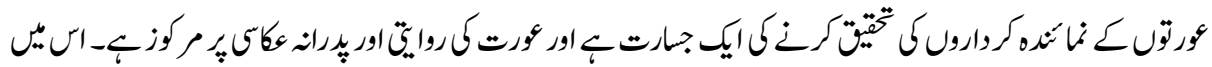

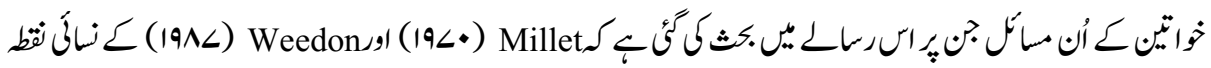

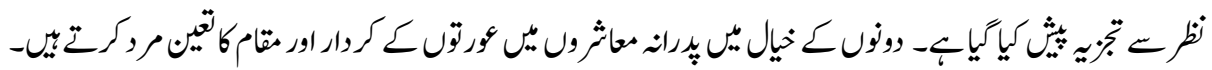

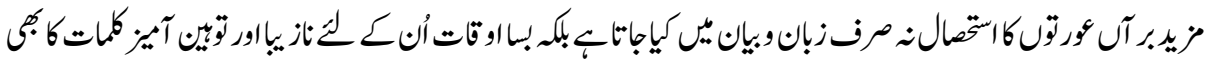

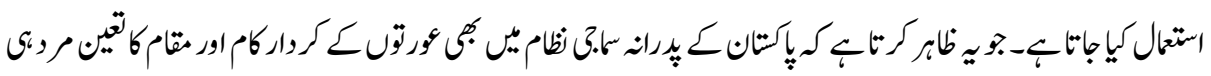

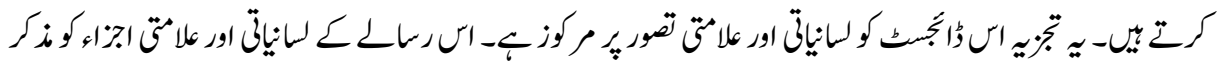

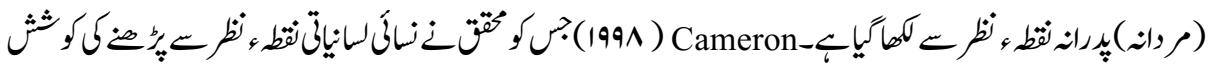




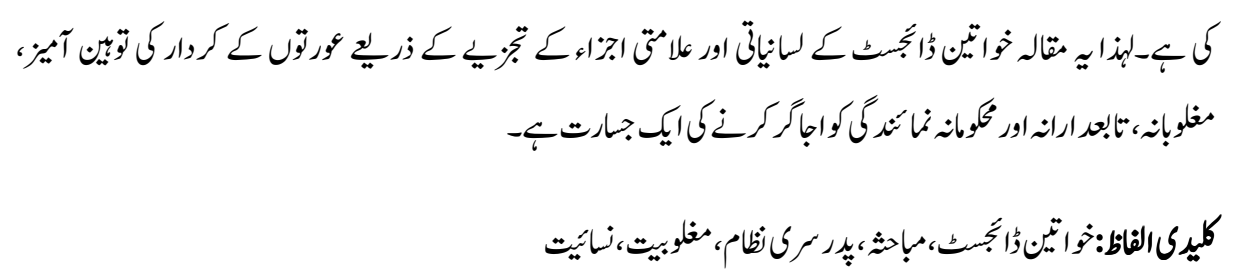

\section{Introduction}

Femininity is specifically a socially constructed ideal in patriarchal social order of Pakistan. Diverse ideologies and cultural beliefs about femininities are encoded in languages differently. According to the feminine perspective, my subjectivity _ the term refers to conscious and unconscious thoughts and emotions of the individual, her sense of herself and her ways of understanding her relation to the world _ to some extent is involved in these discourses. Khan opines:

Feminist methodology rejects the notion that a researcher can be completely detached, neutral, value-free, objective and rational. Feminists regard these attributes as characteristics of masculine ways of relating to the world which are exploitative and controlling. (Khan 1994:14)

The women magazines have been an important repository of the feminine culture in the Pakistani society for years. The magazines that are available to Pakistani women irrespective of their age are primarily a product of popular culture. This popular culture is presumed by women folk to take their issues seriously. This is true as these magazines change with women reality and are by and large written by women about the women issues (Hodge and Kress, 1993). But unfortunately the serious content that is written in these magazines is paid for with advertisement for beauty tapping and household products.

The representation of social issues is essential. This is because every individual would build up their imagination when interpreting it. The mass media present the decisive and exclusive face of any society (Kellner, 1995). Magazines are essential elements in our lives. These magazines help women to think and build up their selfimage and then reproduce it in the way that is acceptable to a culture. A magazine presents the expected social interactions awaiting a woman in a given culture. Discourse in its broader sense is the context through which awareness and understanding can be constructed. It sets the tone of how people in a particular society decode the meanings and interpretations for various profound activities in a society. In a narrower sense, discourse is an excellent tool to judge a society and its people. KHAWATEEN DIGEST is an important magazine that has loyal audience in the Pakistani society. 
Women magazines in Pakistan have played their role in constructing and disseminating various ideologies in the society. Although they are still moderate in the perception of portraying the feminist perspective yet there is too much reliance on the advertisements that carries on in instituting the established constrained images of Pakistani woman. However, with the recent boom in media across Pakistan the readership and their new problems and issues are being highlighted. There is a general perception that women in Pakistan are facing extreme difficulties, but the proponents believe that a few issues relating to the issues of women should not be characterized as a general problem of the women population. More importantly, since Pakistan has a huge rural population, the issues of women living in rural areas are diverse and different in nature as compared to women residing in urban areas. The case of Mukhtaraan Mai, for instance, would not have gained attention, if it had happened twenty five years back. Therefore the onus is on the MAGAZINES and the DIGESTS that are published in Pakistan. These circulations are an integral part of how women can portray themselves in future.

The magazines that women read are regarded as a social institution (Hermes, 1995). Even though the women magazines in Pakistan have formed and also influence the hope of Pakistani women in pursuance of their female identity, still a large number of women are not sure if these magazines would be able to shape their identity in the Pakistani society. Feminism is cast into the shadows, where at best it can expect to have some afterlife, where it might be regarded ambivalently by those young women who must in more public venues stake a distance from it, for the sake of social and sexual recognition.

The concept of subjectivity and the means by which cultural forms and interpellations (or dominant social processes) call women into being, produce them as subjects whilst ostensibly merely describing them as such, inevitably means that it is a problematically — she, rather than an unproblematically - we, which is indicative of in turn to what we might describe as the emerging politics of post-feminist inquiry. The association of women with magazines has been linked to their domestic role, but not necessarily one which presents women as tied to the kitchen sink. Instead, there is said to be a subversive potential which offers women an opportunity to take time off from domestic chores. This is somewhat outdated now in the view of the number of women who work outside the home.

Magazines have their own particular ethos and ideologies and they can also reflect and construct cultural values. However in order for the text to work, they must draw on reader's knowledge of language. Moreover, in KHAWATEEN DIGEST, the ideologies of beauty, attractiveness, smartness, fairness and of being sexy and seductive were constructed as socially desirable for women. These ideologies were constructed, firstly, 
by playing upon the language through political maneuvering of meanings, idioms, modals, verbs, pronouns, imperatives and figures of speech and secondly, by putting women's body to exploitative and demeaning use.

Women's magazines are generally seen as part of the network of discourses which maintain capitalist-patriarchal definitions of femininity (see for example commentary by Gilbert and Taylor, 1991; McCracken, 1993). Like romance fiction and soap operas, main-stream women's magazines have been critiqued for offering women very constrained sets of meaning about femininity.

\section{Literature Review}

According to Young, -In the past decade, feminist researchers have become increasingly concerned with the ways in which women have been construed within popular media (1989: 173-88).

Most feminists believe that women as a group are treated oppressively and differently from men and they are subject to personal and institutional discrimination. Feminists also believe that society is organized in such a way that it works, in general, to the benefit of men rather than women, i.e, it is patriarchal. Feminism implies commitment to changing the social structure to make it less oppressive to women and, for that matter, to men. For Burton it is essential to distinguish between work which supports an oppressive dominant ideology and work which challenges it, and to state clearly which it is that you are doing (1982:197). Feminism sets itself in opposition to the kind of academic work which aims to mystify the uninitiated and to keep out all but a select few.

Feminist research aims to be accessible, to enable others, to equip women with the skills and knowledge they need or want. According to Lemish (2002), feminist research is inherently linked to action, since it integrates scholarship with activism and seeks a fundamental social change, it encourages researcher's reflexivity upon their personal, social and political positioning, it prioritizes interdisciplinary and multidimensional cooperation; it also encourages non-hierarchical and empowering researcher-researchee relationship and redefines a host of ethical research-related issues. The result is a series of challenges to normative assumptions about conducting and presenting science and philosophy; about the value of social knowledge and its emancipatory implications.

Differing from other branches of action and participatory research, feminist research is particularly concerned with the social construction of gender and condition of women. While there is no unified definition of what makes up feminist thinking or feminist 
methodologies, there are several principles that are central to those defining themselves as feminist researchers. Their work attempts to uncover and challenge male dominance and patriarchal structures and advocates gender equality. For example, feminists (like Millet 1970 and Weedon 1987) have suggested that women's social roles in patriarchal societies are defined by men. Millet (1970) and Moi (1985) have also stated that the way women are represented in literature has an impact on the way they define themselves as subjects in their own lives. In other words, feminism questions the assumption about women's social roles. Mills (1995) in her influential book on sexism in language has contested the underlying assumptions in a range of texts including media images. One of the salient characteristics of feminist theory is its commitment not only to contribute to research and social theory, but also to being a catalyst for a deep social changes (Lemish:2002). Therefore, it rejects many of the central assumptions of normative science regarding the search for universal laws, absolute truths and objective knowledge. Instead, it recognizes that all knowledge is partial and socially situated, and all forms of scholarship are ideological by nature and political by implication. It values researcher's own subjectivity and reflexive abilities and renounces the goal to achieve objectivity and value-free research. Feminist research, as much as action research, is highly politicized and ideologically committed to obtaining, disseminating and integrating knowledge in specific change recommendations, thus assisting in liberating and empowering underprivileged segments of society. Finally, feminist action research is fundamentally committed to enhancing change in what is perceived as the most universal oppression-condition of women world-wide (e.g Cirksena 1996; Cirksena and Cuklanz 1992; Creedon1993; Gallaghar 1998; Houston 1992; Lont 1993).

\section{Discussions}

KHAWATEEN DIGEST is a popular magazine in the already cut throat market. The target market is extensive and people from all walks of life find it as an interesting source of information that best describes the society. The sense of interpretation of different subjects and the availability of extensive matters in our society makes this magazine a success. The stories are just a reminder to the readers of how the society is shaping up and what forces can transform it for a better future.

The dissimilarity in speech can be linked to the different styles of context and genre that are presented in the magazine. Therefore, in many situations, the context may be the same but it might be presenting a different message to the readers. The different contexts used in these stories are therefore the precise variations that make the reader glue to these magazines, so that they can construe different meaning to diverse sources of happenings that take place in a particular society. The expressions that are used in these stories are used in the context of formal as well as informal instances that can be found in daily 
communication. The type of genre or social practice in a conversation plays a very critical role in conveying the personality of the character in the stories.

The femininity carries a strong message in the construction of the magazines that comprise of stories. The conscious and unconscious thoughts and emotions of the women in these stories give the readers a sense of understanding the viewpoint of women in relation to the society. The sense of an individual is the crux of the discourse related to femininity. The speech may victimize women by various patriarchal conversations. On a general note, the femininity of women is consumed in the daily chores of the household activities. Even though, these domestic roles that woman play in their daily lives are essential, it is not the only constituent that constructs the femininity and the ideal image of a woman. Positive self-images of woman can also be constructed through a range of activities that can better control the emotional energy in developing a positive self-identity. The magazine that is under investigation is KHAWATEEN DIGEST.

It reflects the discourse about the relationships in the Pakistani society. The idea of the discourse revolves around the family structure. Family is an extremely important determining factor of an individual's self, their status and their worth in the society. In fact, it would not be a far reaching statement that in Pakistan, the success of an individual is hidden in the 'family tree'. In these magazines the discourses are built and published in such a manner that the reader is able to attach a personal feeling to it. Relations are not only important; they are also very rich in their meaning and interpretations.

The life that the Pakistani woman leads is devoid of any homogenous entity, therefore the discourse that is presented in magazines is inclined to confine the women folk in the domestic affairs. It must be determined what domestic chores are performed by both the bachelor and the married women. The discrepancy is present in the way women have to adjust to the cultural stigmas that are present in the Pakistani society. However, the strength of these stigmas varies as per geographical location in Pakistan. The urban and the independent women have a much higher status, as compared to women living in the rural areas, or even in the remote areas. Also, the essence of 'modesty' is an important constituent in the Pakistani society, as it can have a strong influence on defining what this particular woman is all about. Modesty is important, and is widely cherished in all societies, but, in the Pakistani society, modesty may lead to perversion of facts and the unnecessary duress that is applied on the women folk in our society.

The unevenness in the presentation of the discourse makes these stories more profound and true reflection of the Pakistani society. Therefore, the prior knowledge that the 
readers have about the people and the places presented in the story helps them to get involved with the narrative and compare and contrast the presented discourse with their individual reflection of matters and issues. Therefore, the comparison between the two sides of the pictures (the one presented in the discourse and the other that the reader already possesses) not only can differ, but the reader is also able to interpret the situation from an entirely different perspective.

The Feminine issues are the crux in magazines like 'KHAWATEEN DIGEST' allencompassing messages that are portrayed in the entire magazines are to come to terms with the harsh realities of life. These realities may come about due to tension in relationship between the opposite genders (husband \& wife), or between the same gender (daughter in law and mother in law, father \& son etc). The general messages are to love and learn to love even in the most trying times and conditions. Also, the stories tell us to develop the habit of forgiving people and show restraint towards the negative traits of people.

The discourse that is presented in KHAWATEEN DIGEST is interactive and every story or segment has a distinct meaning. This communication process is based on arguments and counter arguments and the expressions of the people involved in these stories are devoid of any boundaries and limitations. Many social practices that take place in the Pakistani society are well documented in these stories. The discourse is not only explicit, but the non-verbal cues in discourse are well presented in these stories.

For instance, "Ussney kandhay uchkayaye (He shrugged his shoulders!), is a non-verbal clue that is used during the discourse. This is a kind of implicit discourse that can be found in abundance in these stories. Moreover, other important elements of discourse that may comprise of appearance, version, criticism, illumination, and variation of the personalities can be readily found in these stories.

The discourse in KHAWATEEN DIGEST replicates and constructs a subordinate position of women in the Pakistani society. The tone used in these DIGESTS encompasses some of the most important elements for women in their individual lives. Beauty, affection and obedience are some of the themes to name a few that are used in excess in the society. It must also be noted that the discourse also has some stereotypes for different classes and societal predispositions. For instance, the landlord (Waderas, Zamindars) are more often than not depicted as a ruthless bunch of people irrespective of their gender. Even though in real lives the media as well the average individual have stereotypes for this group, the presentation of this group in societies is based on the horrific crimes they carry out against peasants and subordinates. Rural Pakistan is an important theme for these DIGESTS and the discourse that surrounds a woman landlord is not constructed in a positive manner. At one end of the spectrum a woman is extremely 
powerful, whereas another woman is powerless and vulnerable. This is not untrue, but vulnerability of women may occur due to various reasons. The language presented usually shows male as a dominating force, however there is significant change in the current trends that have shown women as more agile, powerful and independent in making decisions.

As Pakistan has become more media centric in recent years, the way women have shown their predisposition towards the society is a mushrooming facet of our culture. The element of oppression is slowly but surely disappearing, nevertheless, diverse socialization and familiarity of incident makes issues simple as well as complicated. Since, the discourse is presented by several authors, sometimes the context of a particular situation may be stressed upon, or another time it may be loosely connected to the context. These differences may erupt from the mindset of the writer and all the elements that may impact the writing have an influence on the way it is presented in the stories. However, what makes the discourse a reality is the construction of the dialogues and the different instruments that makes them lively and energetic. The researcher will present a few examples from the magazine KHAWATEEN DIGEST to present a picture as to how different kinds of expressions in communication are used by the writers of these stories.

This chunk is extracted from the August 2006 Edition of KHAWATEEN DIGEST. These dialogues between the father and the daughter can be found on page 189, line 10 from the novel

The conversation starts like this... "Aaj phir itni dair kar dee. (You are so late again today)" the father is inquiring his daughter why she is late from office? The reply of the daughter is "Sorry baba, app ko tou pata hai, mughey apnay boss kay saath hee uthna parta hai.... (Sorry papa, you know I have to leave the office with my boss....)"to this the father replies... "Mein pehlay din sey khilaf hoon tumharee iss job key magar... (I am not in favour of your this job from day one)..." "Mohabbat Khwab-e-safar" written by Rukhsana Nigar Adnan.

Now the discourse that is presented in this story depicts the prevailing relationship between fathers and daughters in our society. This is a general trend that is highlighted in this story. Normally fathers are known to care more for their daughters; but that does not mean that mothers care less for their daughters. This is a societal element, and people irrespective of their social status tend to care more for their daughters. Another important line in this particular dialogue is the father's concern about coming home late from office. Even though this may be a genuine reason, the concern gets more intense as women are also taken for granted and sexual exploitation in the offices is a normal thing. An additional vital element of discourse that is implicit in this conversation is the fact that 
even if the daughter is having any issue at office, she might not feel confident to confide in her father. There are a few social issues and constraints that are present in the relationship between a father and his daughter. The part,

"Mein pehlay din sey khilaf hoon tumharee iss job key magar (I am not in favour of your this job from day one)"

is an implied statement that the father constructs about the way women are treated at offices. There is a sense of danger and apprehension in the father's statement. The Urdu word 'magar' is written as 'but' in English; this one word presents diverse meaning and is representative of the varied and different mindsets that can be found in our society. In the context of the aforementioned discourse, the father seems to be concerned, worried or upset about the daughter. Even though all these words are synonyms in one way or another, in the context of discourse they might present different connotations. For instance, the father may be worried for the fact that since the daughter is working in the capacity of a secretary, the social stigmas that are associated with being a secretary do not help the cause of a working woman. The discourse is an omnipresent constituent of how people feel for women who arrive late from office. They might not say anything on the woman's face, but the gossiping and rumors that may erupt out of this situation may create a nuisance for the woman and her entire family.

These lines can be found on page 246 in the August 2006 KHAWATEEN DIGEST issue. The discourse is between a mother and a daughter. The conversation starts like this

"Mummy, kia koi aik heewaqt mien accha shohar, accha baap, accha beta aur accha bhai nahi ban sakta? (Mom, can't anyone be a good husband, good father, good son and a good brother at the same time?)”.

The discourse that is presented here erupts out of some emotional situation. The relationship that the woman is signifying can be regarded as the most important in our society. Every relationship has its significance, and women associate themselves with all these relations all their lives. It is interesting to note that the inquiry is not about a woman. This may be out of realization that the woman has faced issues in her life due to the aforementioned relations.

Here the woman is inquiring her mother as to what really constitutes a perfect man. The inquiry is to understand the mentality of a man, and how a woman can come to terms with the ever present tensions that are creating problem for the woman. This discourse also reveals plenty about the feeling of woman about men in the society. This may not be the case all the time, but the different faces of men present a constant challenge for women. Here we can also associate this with the prevalent feeling the women have for 
men around the world. However, this statement cannot be taken as all- encompassing, as men are excellent in maintaining strong relationships with the women.

These lines can be found in the June 2006 issue on page 257. The name of the novel is "Yeh tou hona thaa (This was bound to happen)" written by Aasia Razzaq.

These lines are very interesting as well as funny. The scenario is that a boy wants to get close to a woman, but the lady is not willing to accept the proposal of friendship. The girl who is proposed is a bit timid, as, in general associated with Pakistani girls. The boy is shown as obstinate and wants the girl to accept the friendship proposal at any cost. The girl is afraid to do so, because she might get a bad publicity in the vicinity where she lives. She confides with her friend, who is depicted as a fearless girl. The girls give a beating to the boy to the amazement of everyone in the neighbourhood. The boy also gets amazed that a girl gave him a beating. These lines are defying the image of a Pakistani woman. The discourse has shown one girl as timid and the other girl as fearless. The discourse between the two girls also point to the element of 'sisterhood' in our culture. "Mera koi bhai nahi hai (I don't have any brother)" is another important aspect that is presented in this story. Girls, more often than not, feel safer and secure in the presence of their brothers and elder male relatives. Here it is revealed that when brothers and elderly males are not part of the household, people take such families for granted and try to exploit this weakness.

Therefore, the bond between these two gets stronger as we need an individual with whom we can share our issues. Even though, the girl who gave the beating might have acted promptly, but, in due course she is scolded by her mother for acting in an inappropriate manner. Firstly, for a woman to thrash a man in a Pakistani society, and that too in public can become a source of gaining negative hype in the neighbourhood, therefore the girl's mother is absolutely right that she must abstain from acting in such a manner in future. This is illustrated in the next paragraph on page 258 , where the mother is showing concern for her daughter's actions. This is due to the fact that in our society, it much easier for woman to be made as a scapegoat. The lines point out to this very fact that woman is a weaker gender as pointed out by the author. The argument that is constructed in the discourse engages in identifying the altering viewpoint of the women projected in these stories. This becomes the tool for the author to portray the different versions of woman in the same story. However, one thing must be remembered that the author is only able to influence the behaviour of the woman in a particular setting, and this cannot be construed for every situation. The reason is that the author projects a woman in a particular way that suits the context of that particular story. To support the position of the woman several contexts are designed in the story. 
Since the audience of these stories is predominantly women, 'spin' is given to the argument to make it more compelling and forceful. This is derived from the different situations that women undergo and the different versions of relationships in our society. Therefore, it would not be unfair to say that the reader is spellbound by the discourse that is presented in the analysis. Rationality is built through the depiction of real roles that these women play in their lives. As Pakistani household is closely knit, there can be several variations available to be embedded in the literature. Audiences of the magazine KHAWATEEN DIGEST is predominantly woman, but men are also interested in reading it, as it presents the terse and bitter situation that men also face in their lives. Therefore, gender boundaries are crushed, and the discourse also gets more interactive, as men as readers and characters in the stories provide a balancing act to the discourse. Persuasion is another important trait and it affiliate and urges the different point of views that can be extracted from the discourse. The reader and the author gets closer during the course of communication, as many hypothetical situations presented in the stories are the situations that are real for the readers. Therefore, a special relationship evolves between the reader and the author of the story, but at the same time the argument that is presented by the story is also rejected by the readers, as the women may want the discourse to follow a certain path till its conclusion. This situation is extremely interesting, where the discourse becomes so absorbed, and the feeling of spellbound may convert into uneasiness or at times agitation from the readers. This

agitation may be documented to the editor of the magazine about a particular discourse that has left the reader uneasy and dissatisfied.

The examples that are extracted from KHAWATEEN DIGEST best describe the analysis of femininity and the obvious behavioural outcomes. In addition to the fact that since planned audiences can frequently have indistinct margins, repeatedly the individuality of the community remains indefinite. Without a doubt, it is dependent on whether, and if so to what degree, the society, for a precise case presented in the stories, corresponds with the overall mindset of the society.

\section{Conclusions}

The speech has the power to amend or confirm the viewpoints of persons in a culture. The Urdu magazine, KHAWATEEN DIGEST is constructing very constrained sets of femininity based on traditional and patriarchal representation of female images. The feminine issues of Pakistani woman as depicted in KHAWATEEN DIGEST are based on the traditional customs of the society. Therefore, the stuff that is revealed in the stories in this DIGEST may not essentially be the exact representation. KHAWATEEN DIGEST can be observed as having a subtle effect on woman. The voice may even go quite as stories do depict the prime feature of woman as obedience. 


\section{References}

Burton, D. (1982). 'Through Dark Glasses, Through Glass Darkly', in R. Carter (ed.), Language and Literature, London: Allen \& Unwin, pp.195-214.

Burton, D. (1982). Through dark glasses, through glass darkly‘, in R. Cater (ed.) Language and Literature, London: Allen \& Unwin.

Cameron, D. (1998). Feminist Critique of Language, London: Routledge.

Cameron, D. (1992). Feminism and Linguistic Theory, Basingstoke: Macmillan.

Cirksena, K., \& Cuklanz, L. (1992). Male is to female as -- is to --: A guided tour of five feminist frameworks for communication studies. In L. Rakow (ed.), Women making meaning: New feminist directions in communications. New York: Routledge, pp.18-44.

Cirksena, K. (1996). 'Feminism after Ferment: Ten Years of Gendered Scholarship in Communications', In D. Allen, R.R. Rush, and S.T. Kaufman (eds.). Women Transforming Communications: Global Intersections, Thousand Oaks: CA: Sage, pp.153-160.

Creedon. J. W. (1993). (ed.), Women in mass communication, Newbury Park, CA: Sage.

Gallaghar, M. (1998). 'A Feminist Paradigm for Communication Research', In B. Dervin, L. Grossberg, B.J.O Keefe and E. Wartella (eds.) Rethinking Communication Volume 2: Para digm exemplars, Newbury Park, CA: Sage, pp. $75-87$

Gilbert, P and S. Taylor (1991). Fashioning the Feminine: Girls, Popular Culture and Schooling, Sydney: Allen \& Unwin.

Hermes, J. (1995). Reading Women's Magazines: An Analysis of Everyday Media Use. Cambridge: Polity Press.

Hodge R, Kress, G. (1993). Language as Ideology, London: Routledge. (ed., 2) 
Houston, M. (1992). 'The Politics of Difference: Race, Class and Women's Communication', In L. F. Rakow (ed.) Women Making Meaning: New Feminist Directions in Communication, NY: Routledge, pp.45-59.

Keller, C. M. \& Keller, D. J. (1996). Cognition and Tool Use: The Blacksmith at Work. Cambridge: Cambridge University Press.

Khan, N. (1994). 'Introduction, in N. Khan R. Saigal and A. Zia (eds.) Locating the Self: Perspectives on Women and Multiple Identities'. Lahore: ASR.

Kress, G. (1996). Representational Resources and the Production of Subjectivity: Questions for the Theoretical Development of Critical Discourse Analysis in a Multicultural Society, in C. R. Caldas-Coulthard and M. Coulthard (eds.), Texts and Practices: Readings in Critical Discourse Analysis, London: Routledge, pp. 250-271.

Lemish, D. (1997). The Ripple Effect: Pornographic Images in Israeli Advertising', In S. French (ed.) Interpersonal Violence, Health and Gender Politics, Toronto: McGraw Hill Ryer, pp.285-296.

Lont, C.M. (1993). Feminist Critique of Mass Communication Research. In S. P. Bowen and N. Wayatt (eds.), Transforming Visions, Feminist Critique in Communication Studies, Cresskill, NJ: Hampton Press, pp.231.248.

McCracken, E. (1993). Decoding Women's Magazines, London: Macmillan.

Millet, K. (1970). Sexual Politics, London: Virago.

Mills, S, (1995). Feminist Stylistics, USA, London: Mathuen.

Mills, S. (1992). Discourse, USA, Canada: Routledge.

Moi, T (1985). Sexual Textual Politics, London: Mathuen.

Sheikh, A. (2003) A Study in the Discourse of Advertising Unpublished M.Phil thesis, Department of English, Bahauddin Zakariya University Multan.

Weedon, C. (1987) Feminism and Poststructuralist Theory, Oxford: Blackwell 
Young, S. (1989) Feminism and Politics of Power in Gamman, L., \& Marshment, M. The Female gaze: Women as viewers of popular culture. Seattle: Real Comet Press.

Asmat A. Sheikh is Assistant Professor in the Department of English, The Woman University, Multan.

Dr. Naveed Ahmad is Associate Professor in the Department of English, Bahauddin Zakariya University, Multan. 